\title{
A therapeutic alternative in the management of fibromyalgia
}

\author{
Jair Malagón'; Mariana Villaveces ${ }^{2}$; Lluís Manent ${ }^{3}$
}

1 MD, Surcolombiana University, trained in Alternative Medicine at $\mathrm{Na}$ tional Colombia University- Integral Approach to Pain. Graduated course in "Correction of Minor Intervertebral Disorder of Atlas" at Juan N. Corpas University Foundation

2 MD, epidemiologist, Quality Health Manager at Rosario University

3 MD, BA Barcelona University, National Institute of Homeopathy

Corresponding author:

lluis.manent@atlasprofilax.ch

Como citar: Malagón J, Villaveces M, Manent L. A therapeutic alternative in the management of fibromyalgia. Revista Cuarzo 2017; 23(1): 30-38.

Recibido: 21 de marzo de 2017 Aceptado: 24 de mayo de 2017 Publicado: 30 de junio de 2017

Licencia creative commons

\begin{abstract}
INTRODUCTION: Fibromyalgia is a condition that affects up to $5 \%$ of the population and causes significant deterioration of the quality of life for the sufferer, so it is a therapeutic challenge. The objective of the present study was to describe the experience of the AtlasPROfilax ${ }^{\circledR}$ method in patients with fibromyalgia diagnosed according to the criteria of the American College of Reumatology (ACR) 2010.
\end{abstract}

METHODOLOGY: A cross - sectional study with 63 patients with fibromyalgia was done. Patients were monitored two and six months after applying the AtlasPROfilax ${ }^{\circledR}$ method, in order to evaluate the pain level by visual analogue scale VAS and reevaluate ACR criteria in the follow-up appointment.

RESULTS: The average age of patients was 48.5 SD 12.6 years, $95.24 \%$ were female. $100 \%$ of patients improved pain (initial VAS of 8 vs 4 and 3 after two and six months respectively) and these were significant results. A reduction of widespread pain index as well as a reduction in the presence of symptoms such as fatigue, non-restorative sleep and cognitive disorders that are typical of fibromyalgia were also found in $46 \%$ of cases

CONCLUSION: This study has provided evidence of the effectiveness of the neuromuscular stimulation method of the suboccipital musculature called AtlasPROfilax ${ }^{\circledR}$ in the treatment of fibromyalgia. Randomized and controlled studies are required to demonstrate the medium and long term effectiveness of this therapeutic alternative.

KEYWORDS: Fibromyalgia, pain, cognitive disorders, management. 


\section{Introduction}

L Fibromyalgia (FM) is a clinical syndrome of unknown etiology characterized by the presence of chronic pain related to the musculoskeletal system which is diffused and incapacitating, and is usually accompanied by other symptoms such as fatigue, sleep disturbances, stiffness, migraine, irritable bowel syndrome, depression, anxiety or paresthesia in extremities $(1,2)$. FM affects approximately $0.5-5 \%$ of the population (3). It is a condition that generates high morbidity in those who suffer it, with very high disability rates and the treatment is based on giving symptomatic relief. There is currently no defined treatment; various drugs (analgesics, antidepressants, muscle relaxants, etc.) are used, as well as physical activity and rehabilitation, psychotherapy and alternative methods such as acupuncture, thermal therapy and osteopathy, among others (4-10).

FM diagnosis is made from the proposed criteria in 2010 by the ACR (American College of Rheumatology) criteria consisting of two different aspects: first, widespread pain index (Widespread Pain Index [WPI]) and second, the severity scale symptoms (Symptom Severity Score [SS-Score]); to meet the criteria, these symptoms must be present, at a similar level, during the last three months (See Figure 1). Additionally, in order to arrive at a definitive diagnosis, the presence of other pathologies that could explain the generalized pain should be ruled out.

According to the literature, these new criteria correctly classify $88.1 \%$ of cases when compared with the criteria proposed in 1990 and, since they are fundamentally based on the information provided by patients, do not require a detailed physical examination nor any specialized training of the observer (11). It is also considered that the ACR 2010 criteria can be very useful in the quantification of patients' morbidity, since it allows to measure, according to its own reference, symptoms such as chronic fatigue, non-repairing sleep and cognitive alterations; including a list of forty additional items (see attached Table 1), (11). The ACR 2010 criteria have been validated previously by several groups (12-15). Other articles and systematic reviews have linked risk factors for the development of fibromyalgia such as traumatic history, occupation, stress among others (16).

The prevalence of FM in the population has been estimated between 1 and 5\%(3,20-22). As for gender, it is women who suffer most from the disease with a ratio of 9: 1 with respect to men (20); age of onset is between 35 and 55 years (23). It is a disease that affects the biological, psychological and social spheres of the patient and it is considered to be a major health problem because of its prevalence, high morbidity and high rate of utilization and consumption of health resources (24).

Given the above, it is important to find new treatments for the management of this important disease; one of these treatments is the AtlasPROfilax ${ }^{\circledR}$ method

The AtlasPROfilax ${ }^{\circledR}$ method is a set of deep releasing neuromuscular techniques, developed between 1993 and 1996 by the Swiss René-Claudius Schümperli (17). This method is based on the hypothesis of occipito-atlantoaxial joint dysfunction; is focused on specifically normalizing suboccipital musculature, and thereby largely recovering articular tensegrity at the $\mathrm{Co}-\mathrm{C} 1-\mathrm{C} 2$ region. In general terms, the method is usually applied only once in life and because of its high effectiveness, it allows the reconfiguration of the body at the myofascial level (18), while conducting the natural reconstitution of neuro-

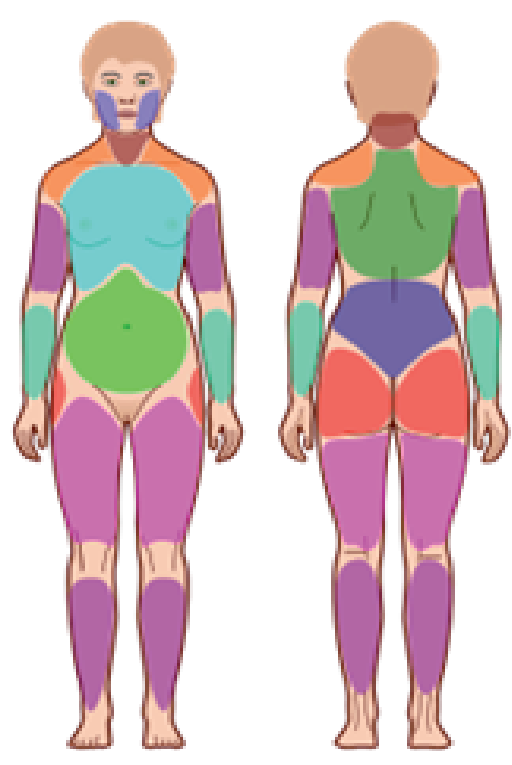

FIGURE 1. Widespread pain index WPI

From: Wolfe F, Clauw DJ, Fitzcharles MA, Goldenberg DL, Katz RS, Mease P, Russell AS, Russell IJ, Winfield JB, Yunus MB. The American College of Rheumatology preliminary diagnostic criteria for fibromyalgia and measurement of symptom severity. Arthritis Care Res,2010;62:600-10. 
vascular structures linked to the cranial- spinal junction (brain stem, bulbomedullary junction, dura mater and vertebro-dural bridge). From a biomechanical point of view, it facilitates the reversal of deformations and alterations in most myofascial chains, improving the static, dynamic, and biomechanical distortion in the body (18). This allows a greater natural tendency to symmetry in the scapular and pelvic girdles, as well as in plantar support. Also, this method is aimed at restoring the tensegritical balance of structures, both soft and rigid of the craniocervical junction, being a method based on the combination of kinesiology and biophysics. Thus, using specific protocols and an apparatus for neuromuscular stimulation with vibropressure, there is a direct effect on the normalization

TABLE 1. Diagnostic criteria for fibromyalgia ACR 2010.

A patient meets diagnostic criteria for fibromyalgia if the following three conditions are present:

1) Generalized Pain Index (Widespread Pain Index - WPI) $\geq 7$ and Symptom Severity Index (Symptom Severity Score - Score SS) $\geq 5$ or WPI 3-6 and $\mathrm{SS} \geq 9$.

2) The symptoms have been present, at a similar level, during the last three months.

3) The patient has no other pathology that can explain the pain.

Testing

1) WPI: List the number of areas where the patient has had pain during the last week. In how many areas have you had pain? The value must be between 0 and 19 .

Areas: Left Scapular Waist, Right Scapular Waist, Left Lower Leg, Right Lower Leg, Upper Left Arm, Upper Right Arm, Left Jaw, Right Jaw, Left Lower Arm, Lower Arm Right, Chest (Abdomen), Hip (gluteal / trochanter) Left, Hip (gluteal / trochanter) Right, Neck (nape and forehead), Upper Back, Back

Lower, Upper Left Leg, and Upper Right Leg.

2) SS Score:

- Fatigue

- Unrefreshing sleep

- Cognitive symptoms

For each of the three indicated symptoms, choose the severity level during the last week, based on the following scale:

$0=$ No problem

$1=$ Light, almost always light or intermittent

$2=$ Moderate, produces considerable problems, almost always present at a moderate level.

$3=$ Severe, persistent, continuous affectation, great affectation of the quality of life.

Consider somatic symptoms in general, indicating if the patient has: *

$0=$ Asymptomatic ( 0 symptoms)

$1=$ Few symptoms (between 1 and 10)

$2=$ Moderate number of symptoms (between 11 and 24)

$3=$ A large accumulation of symptoms ( 25 or more)

The SS score is the sum of the severity of the three symptoms (fatigue, non-restorative sleep, and cognitive symptoms) plus the value of somatic symptoms. The final score should be between 0 and 12 .

* Muscle pain, irritable bowel syndrome, fatigue / exhaustion, problems of comprehension or memory, muscle weakness, headache, abdominal cramps, numbness / tingling, dizziness, insomnia, depression, constipation, epigastric pain, nausea, anxiety, chest pain, blurred vision, diarrhoea, dry mouth, itching, wheezing, Raynaud Phenomenon, urticaria, tinnitus, vomiting, stomach acidity, oral thrush, loss or changes in taste, seizures, dry eye, shortness of breath, loss of appetite, rash / rash, sun intolerance, hearing disorders, frequent ecchymosis, hair loss, frequent urination, painful urination, bladder spasms. 
of the cranio-cervical junction at the myofascial, articular, vascular and neurological levels. $(17,19)$

Since this technique is a novel and easy method to implement (18), it is possible to take this into account as an additional resource in the multidisciplinary approach to the treatment of FM. About six years ago, it was implemented as part of FM management and therefore, the study presents the experience of a cohort of patients in order to demonstrate the benefits of this therapeutic resource, which is not invasive, is devoid of risks, complications and can modify the course and forecast of FM.

\section{Materials and methods}

A cross-sectional study was carried out; including a series of patients seen at personal consultations, diagnosed with FM. AtlasPROfilax ${ }^{\circledR}$ was applied to all patients during the first consultation.

The diagnosis of FM was made with the ACR 2010 criteria as follows: 1) Wide Pain Index WPI $\geq 7$ and symptom severity index -SS Score $\geq 5$; or the presence of a WPI between 3 and 6 and SSS $\geq 9$. 2) That the symptoms have been present, at a similar level, during the last three months. 3) that the patient has no other pathology that can explain the pain (See Table 1).

All patients were given the same questionnaire to assess these indices at the initial consultation and again at 2 and 6 months, together with the measurement of pain using an analogous scale VAS (25).

All results were descriptively analyzed according to the nature of the variables, prior evaluation of normality distribution of the population by the Kolmogorov - Smirnov test (because it is a sample bigger than $n=50$ ). When the data is qualitative, it will be presented in terms of frequencies and proportions. When the data is quantitative it will be presented in terms of measures of central tendency and dispersion. Sociodemographic variables, WPI, SSS and pain level were evaluated using the analogous visual scale VAS at the initial consultation, at two months and at six months afterwards. The use of analgesics like acetaminophen, ibuprofen, diclofenac, naproxen, opiates and pregrabalin among others was also evaluated. To define the difference between pain values before and after treatment, $p$ was calculated by means of a difference test, all values below $p=0.05$ were considered significant.
This study has informed each patient, prior to data collection consent. Consecutive sampling and follow up was carried out for three years.

\section{Results}

In the period from 2014 to 2016 , a total of 63 patients with FM were treated with the AtlasPROfilax ${ }^{\circledR}$ method, and followed-up at 6 months. When evaluating the distribution of the population, it was evidenced that it meets normality criteria $(\mathrm{p}=0.49)$

The average age was 48.5 SD 12.6 years old with a minimum age of 17 and maximum age of 74 years. 95.24\% of the patients were female. In terms of labour status, $34.9 \%$ were employed, $31.75 \%$ were self-employed, $15.87 \%$ were housewives and $17.48 \%$ were pensioners, students, traders, and unemployed. Regarding the level of schooling, the majority of the patients had a university education (41.27\% compared to high school students with $23.81 \%$ and technical / technological training 19.05\% (See Table 2)).

$66.6 \%$ of the patients live in or around Bogotá.

$79.37 \%$ reported some type of traumatic antecedent.

With respect to the findings of the initial consultation, 49 patients $(77.78 \%)$ reported a pain greater than or equal to 8 on the analogue visual scale for pain, $100 \%$ of the patients who entered the study were diagnosed by the WPI criterion $\geq 7 \mathrm{SS} \geq 5,46.03 \%$ of patients had a WPI $\geq 14$ (See Table 3).

$65.08 \%$ used analgesics, among which 27/41 used NSAIDs, 5/41 NSAIDs + opiates, and to a lesser extent NSAIDs with naproxen, local infiltrations, dipyrone, corticoid, and pregrabalin with piroxicam; $9.5 \%$ used opioids for pain control, one patient presented analgesic abuse.

After applying the studied method in the initial consultation, a noticeable decrease in pain was reported by the patients. At the medical check-up at 2 months, all patients had decreased pain, with an average of $4 / 10$ on the VAS scale and 3/10 at 6 months. The difference in pain at the beginning and at the end of the follow-up was statistically significant $(\mathrm{p}=0.03)$. The average pain index at baseline was 13 points, at 2 months it was 7 and at 6 months was 5 on the WPI scale. The difference in pain at the beginning 
and at the end of follow-up was statistically significant ( $\mathrm{p}$ $=0.01$ ). The SSS severity index was 8 on average before the intervention, dropping down to 5 after 2 months and down to 4 after 6 months (p 0.05). (See Table 4).

At the sixth month after applying the method, all patients presented on average WPI and SS scores of 5 and 4 , respectively, which are not sufficient to meet FM diagnostic criteria.

Regarding the evaluation of the fatigue sensation, measured according to the ACR 2010 criteria, $46.3 \%$ of patients rated this symptom as 3 (highest) before receiving the intervention, in contrast to $1.59 \%$ (1 patient) in the evaluation at 6 months. In the assessment of unrefreshing sleep, the $46.03 \%$ of patients assessed this symptom as 3 (maximum degree) before receiving the intervention, in contrast to $3.17 \%$ in the evaluation at six months ( $p=$ $0.01)$. Concerning cognitive disorders, referred to as at- tention, concentration and short-term memory problems, $46.03 \%$ of the patients rated it as grade $2(\mathrm{n}=25)$, and $4 \%$ of patients as grade 3 at the beginning of the study treatment and evaluation grade $220.6 \%$ of patients and grade $30 \%$ at six months $(\mathrm{p}=0.03)$.

\section{Discussion}

As the incidence-prevalence of FM is increasing $(1,2,18)$ and the social, clinical and economic impact is increasing, as is the complexity of its treatment, it is vital to make new resources and therapeutic approaches. Although to date there are no clinical studies that use the AtlasProfilax ${ }^{\circledR}$ method for the treatment of FM, this research managed to establish that there is a significant reduction of pain, from $8 / 10$ to $4 / 10$ at two months and 3/10 at six months as measured by the VAS scale, as well as the reduction in the number of painful areas assessed by the ACR criteria: WPI of 13, WPI of 7 to 2 months and WPI

TABLE 2. Socio-demographic characteristics of the population

\begin{tabular}{|c|c|c|c|}
\hline VARIABLE & CHARACTERISTICS & $\mathrm{N}$ & $\%$ \\
\hline \multirow[t]{2}{*}{ Age } & Average & 48.53 SD 12.6 years & \\
\hline & Min-max & $17-74$ & \\
\hline \multirow[t]{2}{*}{ Gender } & Female & 60 & 95.24 \\
\hline & Male & 3 & 4.76 \\
\hline \multirow[t]{7}{*}{ Work status } & Independent & 20 & 31.75 \\
\hline & Unemployed & 6 & 9.52 \\
\hline & Home / Housewife & 10 & 15.87 \\
\hline & Employee & 22 & 34.92 \\
\hline & Pensioner & 3 & 4.76 \\
\hline & Student & 1 & 1.59 \\
\hline & Merchant & 1 & 1.59 \\
\hline \multirow[t]{6}{*}{ Scholarship } & Primary & 5 & 7.94 \\
\hline & Incomplete Bachelor & 2 & 3.17 \\
\hline & Bachelor & 15 & 23.81 \\
\hline & Technical/Technological & 12 & 19.05 \\
\hline & College & 26 & 41.27 \\
\hline & Postgraduate & 3 & 4.76 \\
\hline
\end{tabular}


Results EVA, WPI and SSS initial consultation

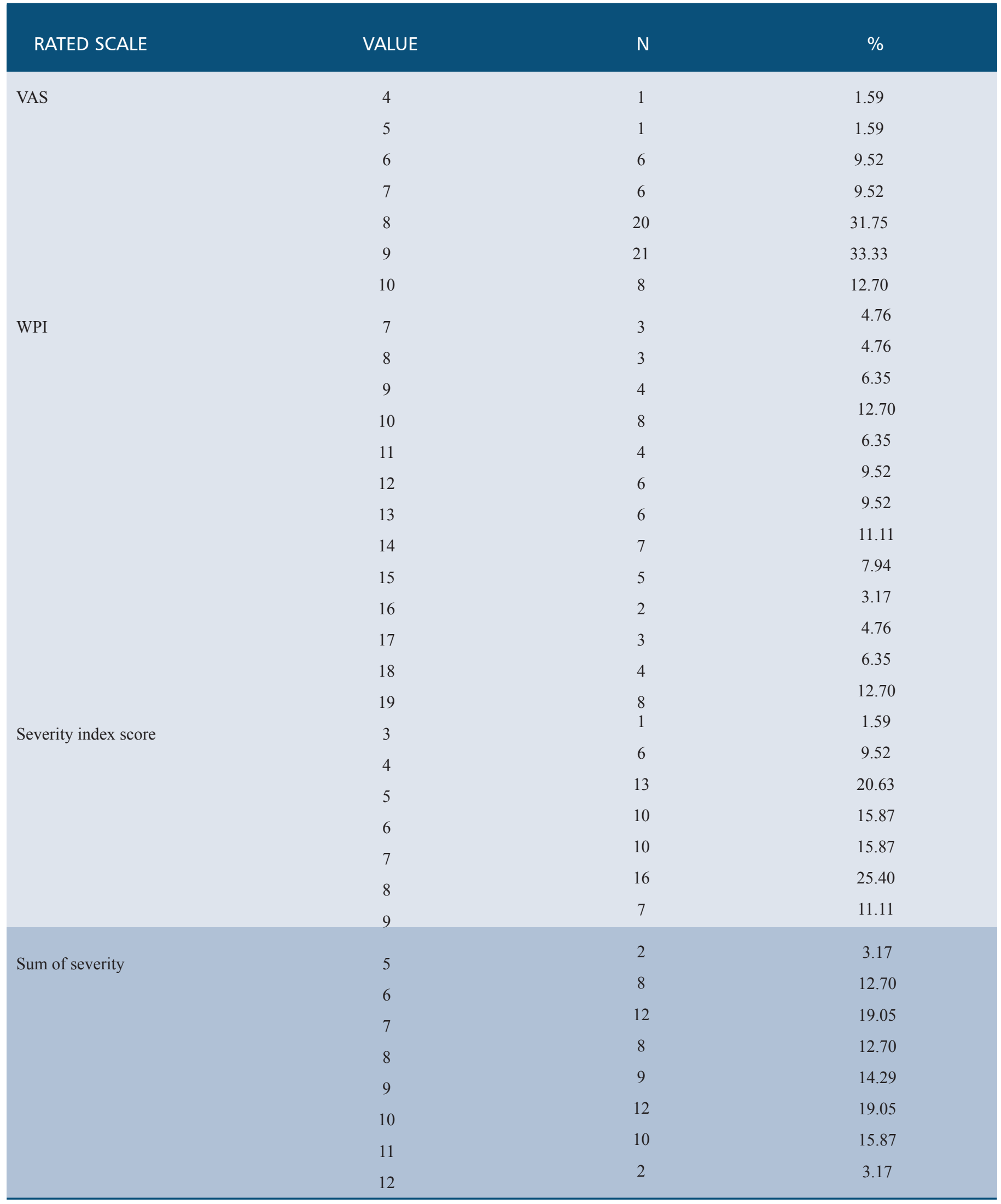


TABLE 4. Relationship of the evolution of patients after receiving treatment.

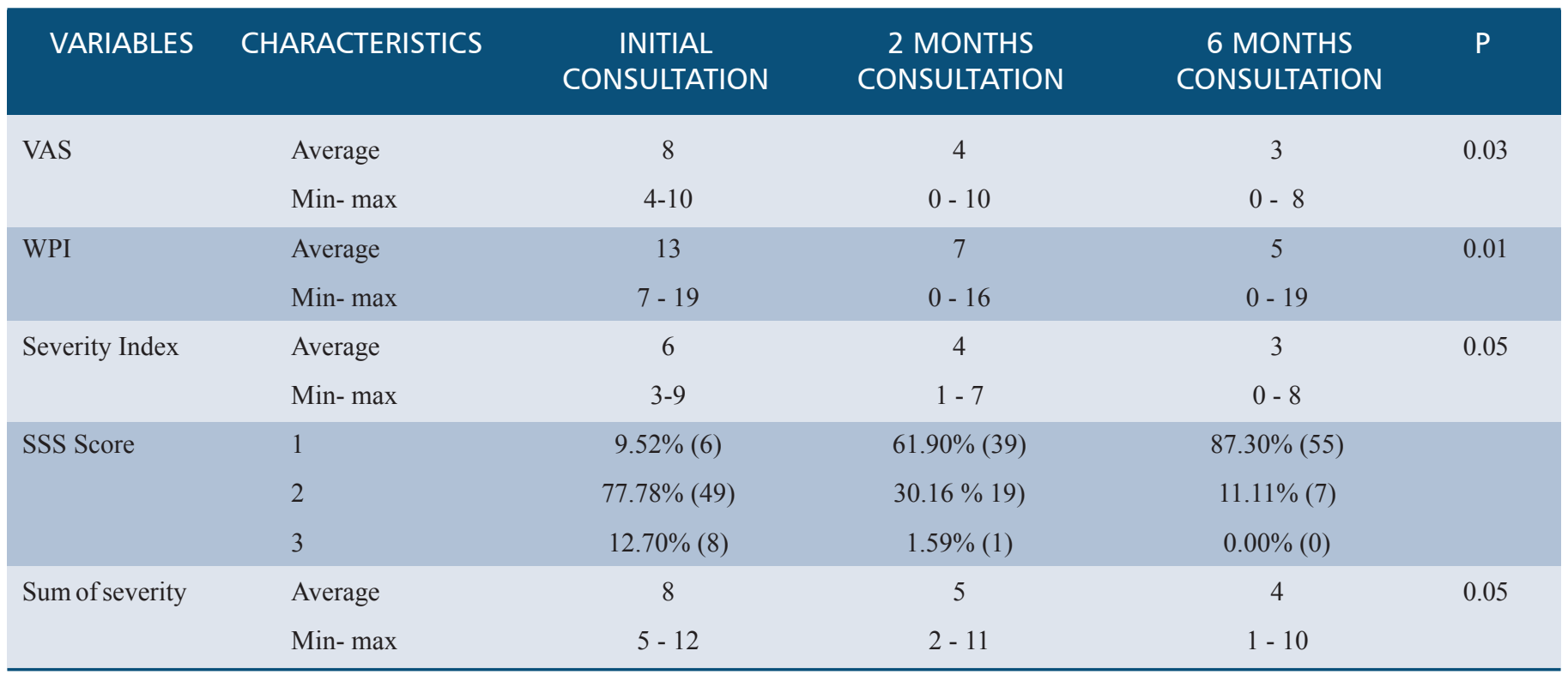

TABLE 5. Relationship of evolution of patients' symptoms after receiving treatment.

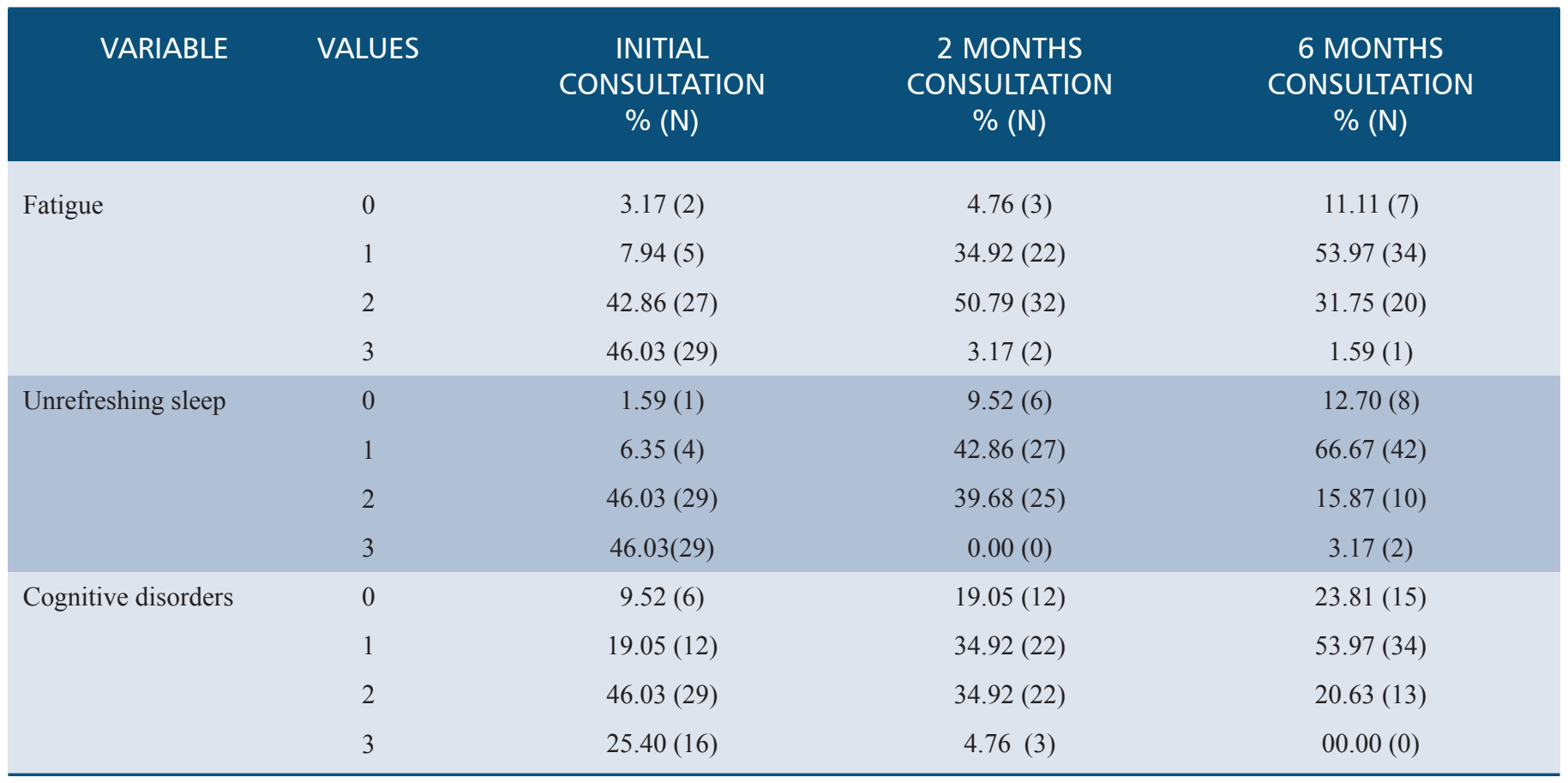

$* * 4$ patients did not attend the 2 nd consultation $* * 1$ patient did not attend the last consultation at 6 months 
of 5 to 6 months, as well as the reduction of annoying symptoms such as fatigue, not repairing sleep, cognitive alterations, among others.

Unlike the AtlasProfilax method, which is a non-invasive, risk-and-complication-friendly method that requires only one intervention, other treatments such as physiotherapy, acupuncture and symptomatic treatment have not presented such clear and promising results (26-28).

A study by Navas (18), with 151 patients, demonstrated the effect of the Atlasprofilax ${ }^{\circledR}$ method on the symptoms related to temporomandibular dysfunction, bruxism and other mandibular deviations, finding that this therapy reduced the symptoms related to this dysfunction in more than $70 \%$ of patients. The study also revealed a reduction in midline deviation in occlusion and opening (18).

The findings of the present study are presented as a starting point for new studies, to demonstrate the effectiveness of this method on a large scale. Since it is a descriptive study, by its nature it does not allow definitive conclusions to be drawn in the management as a single therapy in patients with fibromyalgia, but it is proposed as a line of research for new studies that include, for example, other measurement elements such as algometers in pain points.

\section{Conclusions}

The AtlasProfilax ${ }^{\circledR}$ method, applied in a single intervention, improves FM pain in $100 \%$ of patients, with a statistically significant difference.

Randomized controlled trials are required to demonstrate effectiveness on a large scale.

\section{Acknowledgment}

The author expresses his appreciation to the work team.

Conflicts of interest: The authors report that there are no conflicts of interest

\section{Bibliography}

1. Escudero-Carretero MJ, García-Toyos N, Prieto-Rodríguez MA, Pérez-Corral O, March-Cerdá JC L-DM. Fibromyalgia: Patient perception on their disease and health system. Qualitative research study. Reumatol Clin. 2010;6(1):16-22.
2. Martin AP, Lanza JRL. Evidences in fibromyalgia. FMC Form Med Contin Aten Prim. 2007;14(8):465-73.

3. Häuser W, Eich W, Herrmann M, Nutzinger DO, Schiltenwolf M HP. The Fibromyalgia syndrome: Classification, diagnosis, and treatment. Dtsch Arztebl. 2009;106(23):38391.

4. Rivera J, Alegre C, Nishishinya MB PC. Therapeutic evidence in fibromyalgia. Reum Clin. 2006;2(SPEC. ISS1):34-7.

5. Baranowsky J, Klose P, Musial F, Haeuser W, Dobos G LJ. Qualitative systemic review of randomized controlled trials on complementary and alternative medicine treatments in fibromyalgia. Rheumatol Int. 2009;30(1):1-21.

6. Sarac AJ GA. Complementary and alternative medical therapies in fibromyalgia. Curr Pharm Des. 2006;12(1):47-57.

7. Wang C, Schmid CH, Rones R, Kalish R, Yinh J, Goldenberg DL et al. A randomized trial of tai chi for fibromyalgia. N Engl J Med. 2010;363(8):743-54.

8. Patel NB. Guide to Pain Management in Low-Resource Settings.

9. Matsumoto S, Shimodozono M, Etoh S, Miyata R KK. Effects of thermal therapy combining sauna therapy and underwater exercise in patients with fibromyalgia. Complement Ther Clin Pr. 2010;10(3):201-8.

10. Saudo Corrales B, Galiano Orea D, Carrasco Pez L, Saxton J DHLM. Autonomous nervous system response and quality of life on women with fibromyalgia after a longterm intervention with physical exercise. Rehabilitación. 2010;44(3):244-9.

11. Wolfe F, Clauw DJ, Fitzcharles MA, Goldenberg DL, Kazt RS, Mease P et al. The American College of Rheumatology Preliminary Diagnostic Criteria for fibromyalgia and measurement of symptom severity. Arthritis Care Res. 2010;62(5):600-10.

12. Arnold, Lesley M; Stanford, Sharon B; Welge, Jeffrey A; Crofford LJ. Development and testing of the fibromyalgia diagnostic screen for primary care. J Womens Heal. 2012;21(2):231-9.

13. Segura-Jiménez, Víctor; Aparicio, Virginia A; ÁlvarezGallardo, Inmaculada C; Soriano-Maldonado, Alberto; Estévez-López, Fernando; Delgado-Fernández, Manuel; Carbonell-Baeza A. Validation of the modified 2010 American College of Rheumatology diagnostic criteria for fibromyalgia in a Spanish population. Rheumatology. 2014;53(10):1803-11. 
14. Carrillo-de-la-Peña, M T; Triñanes, Y; González-Villar, A; Romero-Yuste, S; Gómez-Perretta, C; Arias, M; Wolfe F. Convergence between the 1990 and 2010 ACR diagnostic criteria and validation of the Spanish version of the Fibromyalgia Survey Questionnaire (FSQ). Rheumatol Int. 2015;35(1):141-51.

15. Bennett, RM; Friend, R; Marcus, D; Bernstein, C; Han, BK; Yachoui, R; Deodhar, A; Kaell A et al. Criteria for the diagnosis of fibromyalgia: validation of the modified 2010 preliminary American College of Rheumatology criteria and the development of alternative criteria. Arthritis Care Res. 2014;66(9):1364-73.

16. Juan C. Restrepo-Medrano, Elena Ronda-Pérez, Carmen Vives-Cases y DG-G. ¿Qué sabemos sobre los Factores de Riesgo de la Fibromialgia? Rev Salud Publica. 2009;11(4):662-74.

17. R S. Atlasprofilax. Asociación Latinoamericana de Especialistas en AtlasProfilax. Asociación Latinoamericana de Especialistas en AtlasProfilax. 2011. p. www.atlasprofilax.la.

18. Navas VEG. Efecto de la terapia Atlasprofilax ${ }^{\circledR}$ sobre los síntomas relacionados con disfunción temporomandibular, bruxismo y la relación de las líneas medias dentales. UstaSalud. 2013;12(2):124-33.

19. Heike G. Posición viciosa del atlas con rotación e inclinación a la izquierda. Audiolibro. 2017.

20. Guymer E LG. Fibromyalgia: Current diagnosis and management. Expert. Rev Clin immunol. 2009;5(2):181-92.

21. Gómez-Argüelles JM AB. Prevalence of neurological symptoms associated with fibromyalgia. Rev Soc Esp Dolor. 2009;16(4):222-9.
22. Ware MA, Fitzcharles M-, Joseph L SY. The effects of nabilone on sleep in fibromyalgia: Results of a randomized controlled trial. Anesth Analg. 2010;110(2):604-10.

23. Branco JC, Bannwarth B, Failde I, Abello Carbonell J, Blotman F, Spaeth M et al. Prevalence of fibromyalgia: A survey in five European countries. Semin Arthritis Rheum. 2010;39(6):448-53.

24. A Collado, J Alijotas, P Benito, C Alegre, M Romera, I Sañudo, R Martín, J M Peri, J M Cots, J Maria Peri JMC. Documento de consenso sobre el diagnóstico y tratamiento de la fibromialgia en Cataluña. Med Clin. 2002;118(19):7459.

25. Downie WW, Leatham P a, Rhind VM, Wright V, Branco J a, Anderson J a. Studies with pain rating scales. Ann Rheum Dis. 1978;37(4):378-81.

26. A.M. Martín-Nogueras, JIC-A. Efficacy of physiotherapy treatment on pain and quality of life in patients with fibromyalgia. Rehabilitacion. 2012;46(3):199-206.

27. Workspace. 1 NRMA links open the author workspace. O the author workspaceOpens the author workspace1. $\mathrm{N}$ and letters correspond to the affiliation list. $\mathrm{C}$ to expose these in author workspaceMauricio ÁMA links op. Acupuncture as complementary treatment of fibromyalgya. Rev Colomb Reumatol. 2012;19(1):27-39.

28. Jaime Gonzalez Gonzalez, Maria del Mar del Teso Rubio, Carmen Nelida Waliño Paniagua, Juan Jose Criado-Alvarez JSH. Symptomatic pain and fibromyalgia treatment through multidisciplinary approach for Primary Care. Reumatol Clin. 2015;11(1):22-6. 